\section{Monitoração da leucose enzoótica bovina no gado leiteiro da região de Pitangueiras (SP)}

\author{
Monitoring of enzootic bovine leukosis in dairy cattle from the \\ Pitangueiras region in São Paulo, Brazil
}

Samir Issa SAMARA'; Edimo Garcia LIMA²; Adjair Antonio do NASCIMENTO'

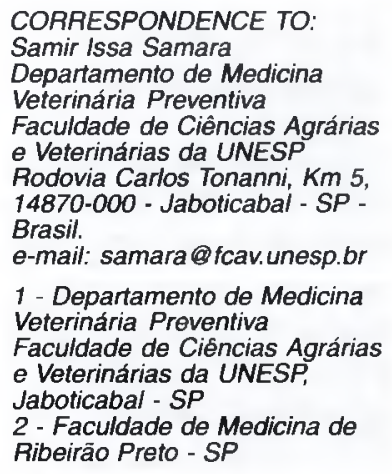

CORRESPONDENCE TO:

Samir Issa Samara

Faculdade de Ciências

e Veterinárias da UNESP

Rodovia Carlos Tonanni $\mathrm{Km} 5$

14870-000 - Jaboticabal - SP -

Brasil.

e-mail: samara@fcav.unesp.br

1 - Departamento de Medicina

Veterinária Preventiva

Agrárias

Jaboticabal - SP

Ribeirão Preto - SP

\title{
RESUMO
}

Anticorpos precipitantes contra o antígeno gp51 do vírus da Leucose Enzoótica Bovina foram pesquisados em amostras de soros de vacas leiteiras da região do município de Pitangueiras, no Estado de São Paulo. As amostras sanguíneas eram de animais provenientes de sete propriedades rurais que foram acompanhadas anualmente de 1992 até 1995 . Durante o ano de 1992 foram analisados 140 soros, dos quais $24(17,1 \%)$ eram reagentes positivos, 21 (15,0\%) suspeitos e 95 (67,9\%) negativos. Em 1993, dos 122 soros testados, 25 (20,5\%) foram positivos, $8(6,6 \%)$ suspeitos e $89(72,9 \%)$ negativos. No ano de 1994 foram testadas 135 amostras, das quais $45(33,3 \%)$ eram positivas, $19(14,1 \%)$ suspeitas e 71 (52,6\%) negativas. Finalmente, em 1995, foram analisadas as amostras de 119 animais sendo que $60(50,4 \%)$ eram positivas, 11 (9,2\%) suspeitas e $48(40,4 \%)$ negativas. Os resultados obtidos evidenciam que no decorrer do experimento houve um nítido aumento na prevalência da Leucose Enzoótica Bovina com o passar do tempo. Sob o prisma da Defesa Sanitária Animal, a crescente disseminação da doença na população estudada serve como alerta sobre o comportamento epidemiológico e sobre a evolução na difusão da enfermidade em nosso meio.

UNITERMOS: Leucose bovina; Gado leiteiro; Diagnóstico; Oncovirus bovino.

\section{INTRODUÇÃO}

A leucose é uma enfermidade que pode se apresentar sob a forma enzoótica, quando relacionada com a infecção viral em bovinos, ou esporádica, representada pelas formas juvenil, tímica e cutânea, porém sem associação com a etiologia viral. Portanto, o termo Leucose Enzoótica Bovina (LEB) é usado para designar a infecção causada pelo vírus da Leucose Enzoótica Bovina (VLB) que determina soro conversão, linfocitose persistente e linfossarcoma ${ }^{14}$.

No Brasil, a LEB não está prevista na política sanitária do governo sobre a importação de bovinos ${ }^{10}$, o que facilitou a entrada no país de animais infectados e consequiente difusão da doença através do comércio intra- e interestadual. Há também outros fatores agravantes na disseminação da enfermidade como, por exemplo, contatos mais estreitos entre doentes e susceptíveis ${ }^{12}$.

A situação da LEB no Estado de São Paulo pode ser comprovada por diversos levantamentos soroepidemiológicos que, utilizando a prova de imunodifusão em gel de ágar (IDGA) e antígeno glicoprotéico gp51, detectaram bovinos com a LEB. A prevalência da infecção do VLB, diagnosticada através da IDGA, foi determinada em nosso meio por diversos pesquisadores $1.2 .3,4,5,6,7,7,9,9,11$, mostrando índices variáveis desde $4,1 \%$ até $60,0 \%$ de positividade.

Assim, tendo em vista que o VLB está comprovadamente disseminado nos bovinos do Estado de São Paulo, tem o presente trabalho o objetivo de determinar a evolução da doença em rebanhos que não são submetidos a qualquer forma de controle ou prevenção. Para tanto realizou-se o estudo epidemiológico em uma região leiteira específica, ou seja, no município de Pitangueiras, fazendo-se o acompanhamento anual de diversos rebanhos a partir de 1992 até 1995.

\section{MATERIAL E MÉTODO}

\section{Área de estudo}

A zona rural do município de Pitangueiras, no Estado de São Paulo, tem como atividade econômica principal as culturas de cana-de-açúcar e secundariamente a exploração leiteira. Nesta última atividade, os rebanhos predominantes são de cruzamento do HPB com raças zebuínas. A produção média das vacas em lactação está em torno de $8 \mathrm{~kg}$ de leite por dia e as criações s̃̃o normalmente realizadas em regime semi-intensivo, em pequenas áreas e usando pouca tecnologia.

\section{Amostra de sangue}

Anualmente, a partir de 1992 até 1995, foram colhidas 516 amostras de sangue de vacas adultas, provenientes de sete propriedades rurais, que foram ou não visitadas mais de uma ve $z$ no decorrer do período deste experimento. O soro sanguíneo, obtido por centrifugação destas amostras, foi acondicionado em frasco de vidro, arrolhado e mantido em congelador $\left(-20^{\prime \prime} \mathrm{C}\right)$ até o momento de ser submetido à prova sorológica.

Prova sorológica

As amostras de soro sanguíneo foram descongeladas e, quando atingiam a temperatura ambiente, foram testadas para pesquisar anticorpos precipitantes contra o VLB através da prova de IDGA desenvolvida por Ouchterlony ${ }^{15}$ (1958). $O$ antígeno utilizado na prova foi o gp51, produzido segundo a metodologia desenvolvida por Lima" (1980), comercializado pelo Laboratório Behring (Ale- 
SAMARA. S.I. IIMA. E.G.: NASCIMENTO, A.A. Monitoração da leucose enzoótica hovina no gado leiteiro da região de Pitangueiras (SP). Braz. J. vet. Res. anim. Sci., São Paulo, v. 34. 11. 6. p. 349-151. 1997

manha). O desenvolvimento da técnica laboratorial e os critérios de leitura foram os mesmos estabelecidos pelo Office Internationnal des Epizooties ${ }^{13}$ (1991).

\section{RESULTADOS}

Os resultados dos animais reagentes na prova de IDGA para a pesquisa de anticorpos contra o VLB são apresentados na Tab. 1. expressos em períodos anuais em cada uma das propriedades rurais. Com base nos valores desta tabela foi construída a Fig. I para ilustrar as alterações obtidas.

Pela análise dos valores, pode-se constatar que durante o ano de 1992 foram analisados 140 animais, dos quais $24(17,1 \%)$ estavam positivos, $2 \mathrm{l}(15,0 \%)$ foram suspeitos e $95(67,9 \%)$ eram negativos. Em 1993, dos 122 animais testados, 25 (20.5\%) foram positivos, $8(6,6 \%)$ suspeitos e $89(72,9 \%)$ negativos. Já no ano de 1994, foram testados 135 animais, dos quais $45(33,3 \%)$ eram positivos, $19(14,1 \%)$ suspeitos e $71(52,6 \%)$ negativos. Finalmente, em 1995, foram analisadas as amostras sanguíneas de 119 animais sendo que $60(50,4 \%)$ eram positivas, II $(9,2 \%)$ suspeitas e 48 $(40,4 \%)$ negativas.

\section{DISCUSSÃO E CONCLUSÕES}

Os resultados do presente trabalho põem em evidência que no decorrer do experimento houve um nítido aumento na prevalência de animais afetados pela $\mathrm{LEB}$ na região de estudo. Os dados obtidos com a reatividade dos animais testados indicam que, no decorrer dos anos de 1992 até o de 1995, houve um aumento de $17,1 \%$ para $20,5 \%$ e depois para $33,3 \%$ e $50,4 \%$ de positividade entre as amostras analisadas nos respectivos anos (Tab. I e Fig. 1). Em outros trabalhos realizados em circunstâncias similares em rebanhos do Estado de São Paulo, vários pesquisadores também haviam mostrado índices alarmantes de infeç̧ão pelo VLB, como os encontrados neste experimento. Assim, Alencar Filho' (1978) determinou positividade em $60.0 \%$ das 40 amostras que analisou, Lima" (1980) em 33,0\% de 106 exames, Birgel et al..$^{4.56,7}(1983,1988 \mathrm{a}, 1988 \mathrm{~b}$ e 1991) determinaram infecção em 53,8\% de 292 animais; 52,6\% de 462; $44.9 \%$ de 1.722 e $42,9 \%$ de 2.708 amostras nos respectivos anos de estudo. Também Birgel Jr. et al. ${ }^{9}$ (1990) diagnosticaram a LEB em

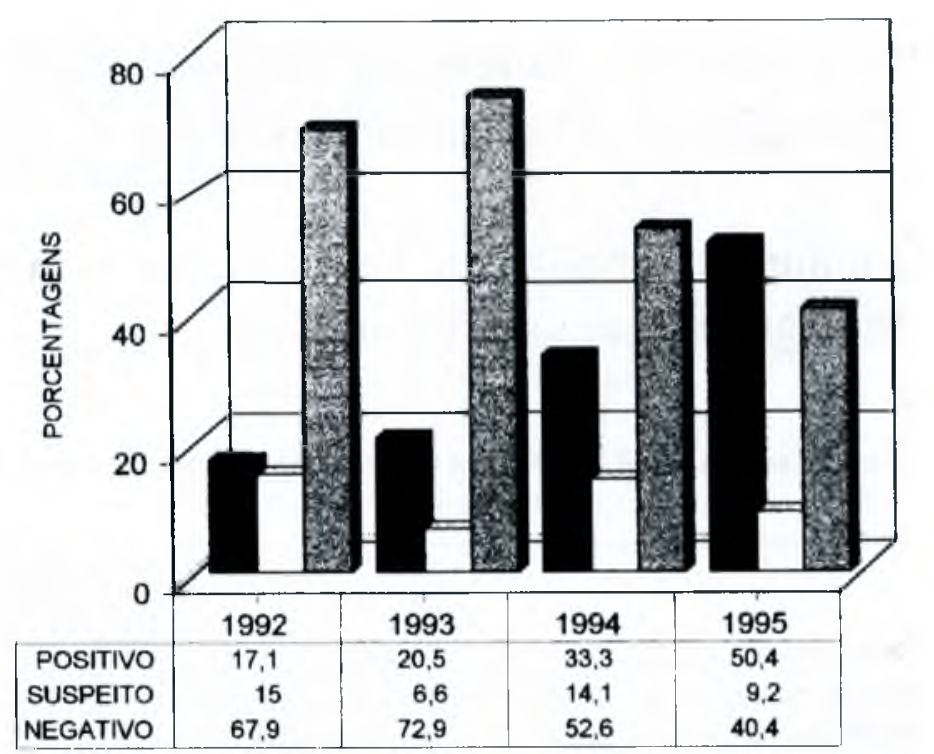

- POSITIVO $\square$ SUSPEITO INEGATIVO

Figura 1

Situação da Leucose Enzoótica Bovina, determinada pelo teste de dupla difusão em gel de ágar com o antígeno gp51, em bovinos da região de Pitangueiras (SP), durante o período de 1992 até 1995.

\section{$45,2 \%$ dos 868 bovinos examinados.}

Índices menores foram obtidos por Alencar Filho et $\mathrm{al}^{2}$ (1979), que determinaram 5,6\% de positivos ao analisarem 1.013 animais, por Arita et al. ${ }^{3}$ (1992), 16,2\% em 2.187 amostras, e por Birgel et $a^{8}$ (1993), 4, $1 \%$ dos exames de 482 animais.

Relativamente à apreciação comparativa dos resultados obtidos a cada ano, este trabalho revela que está havendo um agravamento na situação sanitária da região estudada, no que concerne à LEB A certeza da validade na forma de diagnóstico utilizada comprovada pelo trabalho de Olson; Miller $^{14}$ (1987), associada à lalta de um meio de controle e prevenção da LEB, evidencia que ná região fisiográfica de Pitangueiras (SP) só pode estar ocorrendo um aumento na disseminação da enfermidade com o decorrer do tempo.

Tabela 1

Resultado da imunodifusão dupla em gel de ágar para diagnóstico da Leucose Enzoótica Bovina, na região de Pitangueiras (SP), durante o período de 1992 até 1995.

\begin{tabular}{|c|c|c|c|c|c|c|c|c|c|c|c|c|c|c|c|c|c|}
\hline \multirow{2}{*}{$\begin{array}{c}\text { PROPRIE- } \\
\text { DADES }\end{array}$} & \multicolumn{3}{|c|}{1992} & \multicolumn{5}{|c|}{1993} & \multicolumn{4}{|c|}{1994} & \multicolumn{4}{|c|}{1995} & \multirow[b]{2}{*}{ A } \\
\hline & $P$ & $S$ & $N$ & $T$ & $P$ & $S$ & $N$ & $\mathrm{~T}$ & $P$ & $S$ & $\mathbf{N}$ & $\mathrm{T}$ & $\mathbf{P}$ & $S$ & $\mathrm{~N}$ & $T$ & \\
\hline $\mathrm{I}$ & 5 & 5 & 6 & 16 & 4 & 2 & 11 & 17 & NT & NT & NT & NT & NT & NT & NT & NT & \\
\hline III & 3 & 4 & 14 & 21 & NT & NT & NT & NT & 3 & 0 & 19 & 22 & 11 & 1 & 11 & 23 & \\
\hline IV & 1 & 2 & 24 & 27 & 3 & 1 & 13 & 17 & NT & NT & NT & NT & 5 & 1 & 9 & 15 & \\
\hline V & 11 & 7 & 15 & 33 & 7 & 3 & 34 & 44 & 8 & 8 & 11 & 27 & 30 & 7 & 7 & 44 & \\
\hline TOTAL & 24 & 21 & 95 & 140 & 25 & 8 & 89 & 122 & 45 & 19 & 71 & 135 & 60 & 11 & 48 & 119 & \\
\hline PORCENT. & 17,1 & 15,0 & 67,9 & 100 & 20,5 & 6,6 & 72,9 & 100 & 33,3 & 14,1 & 52,6 & 100 & 50,4 & 9,2 & 40,4 & 100 & \\
\hline
\end{tabular}

$\mathrm{P}=$ positivo; $\mathrm{S}=$ Suspeito; $\mathrm{N}=$ Negativo; $\mathrm{T}=$ Total; $\mathrm{NT}=$ não testado. 
Também no que concerne à infecção, Lorenz; Straub ${ }^{12}$ (1987) observaram que o tipo de manejo é um fator de risco que permite o maior contato dos susceptíveis com a fonte de infecção, ou seja, animais criados em condições de restrição do espaço físico que ocupam têm maior possibilidade de se infectar. Todas as propriedades rurais que foram base para o presente estudo têm como características ambientais as criações de bovinos em pequenas áreas remanescentes dentro do plantio da cana-de-açúcar.

Sob o prisma da Defesa Sanitária Animal, a crescente disseminção da LEB na população pesquisada serve de alerta sobre o comportamento epidemiológico e sobre a evolução da difusão da enfermidade que pode ocorrer com o passar do tempo, se nenhuma medida for tomada visando a prevenção e controle da doença.

\section{Agradecimentos}

Os autores agradecem a colaboração das funcionárias Andréa Souza Ramos de Medeiros, Maria do Carmo Gladenucci Boer e dos acadêmicos do Curso de Medicina Veterinária que cursaram a Disciplina de Enfermidades Infecciosas dos Animais, durante os anos de 1992 a 1995, todos da Faculdade de Ciências Agrárias e Veterinárias de Jaboticabal-UNESP, além do Técnico Agropecuário Pedro Carlos Zabotto da Assistência Nestlé aos Produtores de Leite (ANPL).

\section{SUMMARY}

Serum samples of dairy cows from the region of the municipality of Pitangueiras, State of São Paulo, were investigated for the possible presence of precipitating antibodies against the gp51 antigen of Enzootic Bovine Leukosis. Blood samples were obtained from animals belonging to seven rural properties which were followed up on a yearly basis, from 1992 to 1995 . A total of 140 serum samples were analyzed in 1992. Of these, $24(17.1 \%)$ reacted positively, $21(15.0 \%)$ were suspect and 95 $(67.9 \%)$ were negative. In 1993 , of the 122 samples tested $25(20.5 \%)$ were positive, $8(6.6 \%)$ were suspect and $89(72.9 \%)$ were negative. In 1994, of the 135 samples tested, $45(33.3 \%)$ were positive, $19(14.1 \%)$ were suspect and $71(52.6 \%)$ were negative. Finally, 119 samples of serum were investigated in 1995,60 of which $(50.4 \%)$ were positive, $11(9.2 \%)$ were suspect and $48(40.4 \%)$ were negative. These results demonstrate that a sharp increase in the prevalence of Enzootic Bovine Leukosis occurred during the experiment. From the viewpoint of Animal Sanitary Defense, the growing dissemination of the disease in the studied population serves as a warning about the epidemiologic behavior and about the evolution of the diffusion of the disease in Brazil.

UNITERMS: Bovine leukosis; Dairy cattle; Diagnosis; Bovine oncovirus.

\section{REFERÊNCIAS BIBLIOGRÁFICAS}

1 - ALENCAR FILHO, R.A. A imunodifusão como recurso diagnóstico da leucemia linfática crônica em bovinos. O Biológico, v.44, n. 1, p.27-8,1978.

2 - AI.ENCAR FIL.HO, R.A.; MAZANTI, M.T.; SAAI), A.I); POHL, R. Levantamento preliminar da infecção pelo vírus da Leucemia Linfática Crônica (L.L.C.) dos bovinos no Esiado de São Paulo. O Biológico, São Paulo, v.45, n.3-4, p.47-54. 1979,

3 - ARITA, G.M.M.; GONÇAI.VES, C.D.; SABER, A.F.: GERMANO, P.M.L.; DEAK. J.G.: KOTAIT, I. Estudo epidemiológico da leucose enzoótica dos bovinos no Vale do Parába, São Paulo, Brasil. In : REUNIĀO ANUAI. DO INSTITUTO BIOLÓGic O DE SÃO PAUlO, 5, São Paulo, 1992. Anais. São Paulo, Secretaria da Agricultura e Abastecimento do Estado de São Paulo. 1992. p. 30

4 - BIRGEL, E.H.; DANGIIIINO, J.L.; BENESI, F.J.; HAGIWARA, M.K.; PRADO. M.S.S. Consideraçôes sobre a leucose enzótica dos bovinos adultos em rebanhos leiteiros criados no Estado de São Paulo. I - Prevalência de soro-reagentes. In: SIMANA DE VETERINÁRIA DA FMVZ-USP, 2, São Paulo, 1983. Anais. p.70.

5 - BIRGEL, E.H.; DANGiEl.JNO, I.I .; GARCIA, M.; MARÇAL, W.S. Estudo preliminar sobre a ocorrência da leucose dos hovinos adultos $\mathrm{cm}$ a nimais criados na Região de Campinas. In: CONIFERENCIA ANUAL DA SOClEDAI)E PAUI ISTA IDE MIIDICINA VETERINÁRIA, 43, Campinas, 1988a. Anais. São Paulo. Sociedade Paulista de Medicina Veterinária, 1988a. p.30.

6-BIRGEL, E.H.; D ANGELINO, J.L .; GARCIA, M.: ZOGNO, M.A. Ocorrência da infecção causada pelo vírus da leucose bovina $\mathrm{em}$ gado leiteiro criado no Fstado de São Paulo. Avaliação pela deteceção de anticorpos séricos por imunodifusão com antígeno viral. In: CONFERÊNCIA ANUAL DA SOCIEDADE PAUI ISTA DE MEDICINA VETERINÁRIA, 43, Campinas, $1988 \mathrm{~b}$. Anais. Sāo Paulo, Sociedade Paulista de Medicina Veterinária, 1988. p.31.

7 - BIRGEL, E.H.; DANGELINO, J.L.; GARCIA, M.; BENESI. F.J.; ZOGNO, M.A. Ocorrência da infecção pelo vírus da leucose bovina no estado de São
Paulo. Brazilian Journal of Veterinary Research and Animal Science, v.28. n. 1, p.67-73, 1991.

8 - BIRGEL, E.H.; BENESI, F.H.; D ANGELINO, J.L.; AYRES, M.C.C.; COSTA J.N.; FILHO, I.R.B. Prevalência da leucose enzoótica dos bovinos em zebuínos da raça nelore criados no Estado de São Paulo. In: CONGRESSO PAULISTA IE MEDICINA VETERINÁRIA, 2, São Paulo, 1993. Anais. São Paulo, EDUSP, 1993. p.41

9 - BIRGEL Jr.. E.H.; D ANGELINO, J.1 _.; BENESI, F.J .; BIRGEL, E.H. Prevalência da leucose enzótica dos bovinos adultos em animais da raça Jersey, criados no Estado de São Paulo, Brasil. In: CONGRESSO MUNDIAI. DH BUIATRIA, 16, Salvador, 1990. Anais. Salvador, Interlink Consultoria e Eventos L.dua., 1990, p.789-92.

10 - GONÇAI.VES, E.I. Manual de defesa sanitária animal. Jaboticabal, Funep 1990. p.79-81.

11 - LIMA, E.G. Contribuição para o estudo do diagnóstico de leucemia bovina. Revista de Patologia Tropical, v.9. n. ]-2, p. I-12, 1980.

12 - LORENZ, R.J.; STRAUB, O.C. The epidemiology of en\%otic bovine leukosis. In: BURNY, A.; MAMMERICKY, M. (eds.), Enzootic bovine leukosis and bovine leukemia virus. Boston, Martinus Nijhoff, 1987. p.51-68.

13 - OFFICE INTERNATIONAL. DES EPIZZOTIES (OIE). Manual of recommended diagnostic techniques and requirements for biologic products. Paris, Office International des Epirzotics, 1991 . v.3. p. 1/9-9/9.

14 - OLSON, C.; MIL.LER, J. History and terminology of enzootic bovine leukosis. In: BURNY, A.; MAMMERICKY, M. (eds.). Fnzootic bovine leukosis and bovine leukemia virus. Boston, Martinus Nijholf, 1987, p.3-11]

15 - OUCHTERI.ONY, O. Diffusion in gel methods for immunological analyses. Progress of Allergy, v.5, n. I, p. I-78, 1958 